\title{
The influence of dietary conjugated linoleic acid (CLA) on serum leptin concentration in lactating sows.
}

\author{
C. Corino ${ }^{1}$, D. Magistrelli ${ }^{2}$, V. Bontempo ${ }^{1}$, F. Rosi $^{2}$ \\ 1 Department of Veterinary Sciences and Technologies for Food Safety, University of Milan, Via Celoria 10, 20133 \\ Milan, Italy. \\ ${ }^{2}$ Istituto di Zootecnia Generale, Facoltà di Agraria, University of Milan, Via Celoria 2, 20133 Milan, Italy.
}

Introduction Conjugated linoleic acid (CLA) is a mixture of geometrical and positional isomers of linoleic acid. Health-promoting properties of CLA, which include antioxidant, anti-obesity and anticarcinogenic activities, have been demonstrated in a wide range of animal models (Pariza et al., 2001). Recent studies indicated the CLA has a favorable effect on immune competence in nursery (Bassaganya-Riera et al., 2001) and weaned pigs (Corino et al., 2001). For this reason CLA may be useful in sow nutrition to increase CLA content in colostrum and milk (Bee, 2000). However CLAfed animals displayed also significantly reduced body fat (Pariza et al., 2001) and this effect may be detrimental to reproductive efficiency in sows per se and for the effects on metabolic hormones as well. Moreover some CLA isomers has been reported to influence leptin gene expression (Houseknacht et al., 1998). The present study examined the effects of dietary supplement of CLA on serum leptin in lactating sows.

Materials and methods Sixteen Large White sows were divided into two experimental groups, control and treated. Starting on 15 days before parturition and continuing through lactation, treated animals were fed the control diet supplemented with $0.5 \%$ CLA preparation in free fatty acid form. The CLA mixture contained approximately $50 \%$ of pure CLA isomers, $50 \%$ cis 9 , trans 11 isomer, and 50\% trans 10, cis 12 isomer (from certificate of analysis provided by the manufacturer). Body weight and Body Condition Score (BCS) were recorded before parturition and at weaning (21 d). Feed intake was measured daily. Blood samples were taken at 2, 10 and 20 days of lactation. Serum leptin concentrations, expressed as $\mathrm{ng} / \mathrm{mL}$ human equivalent (HE), were determined with a commercially available radio-immunoassay procedure; the antibody was raised against human leptin and displayed $67 \%$ cross-reactivity to porcine leptin and detection limit of $1 \mathrm{ng} / \mathrm{ml} \mathrm{HE}$ (Multi-Species Leptin RIA Kit, Linco Research Inc., MO, USA).

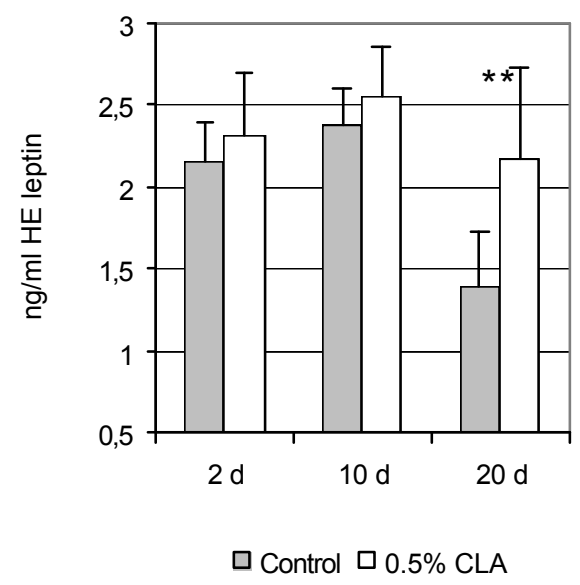

Fig.1 Serum leptin in lactating sows (mean \pm s.d.)

Results CLA dietary supplementation did not affect body weight and BCS of the sows during lactation (Table 1). Average daily feed intake tended to be lower in CLA supplemented sows than in control, although no significant difference was observed. Average serum leptin concentration resulted significantly higher in sows fed CLA (2.37 vs 2.01 $\mathrm{ng} / \mathrm{ml} \mathrm{HE}$, s.e.m=0.08) $(\mathrm{P}<0.01)$ (Figure 1). However it does not seem to be a relation between daily feed intake, body condition of sows during lactation and leptin release.

Tab.1 - Feed intake, body weight, and body condition of

Conclusions These results indicate that dietary CLA does not influence feed intake and body condition. in lactating sows. By these results it does not seem that circulating leptin in lactating sows may be related by body weight and body condition as established in humans and rodents. Further research could explain if the higher leptin level in CLA fed sows is due to changes in leptin gene expression or in leptin clearance as well.

\begin{tabular}{lccc}
\hline & Ctr & CLA & P \\
\hline Sows, $\mathrm{n}$ & 8 & 8 & \\
Daily feed intake, kg/d & $4.54 \pm 0.63$ & $.28 \pm 0.70$ & \\
Body weight, kg & & & $\mathrm{ns}$ \\
$\quad$ Before parturition* & $225 \pm 31$ & $233 \pm 44$ & \\
$\quad$ At weaning (21 d) & $201 \pm 28$ & $202 \pm 42$ & $\mathrm{~ns}$ \\
BCS** & & & $\mathrm{ns}$ \\
$\quad$ Before parturition & $2.65 \pm 0.32$ & $2.68 \pm 0.19$ & \\
$\quad$ At weaning & $2.34 \pm 0.42$ & $2.36 \pm 0.35$ & $\mathrm{~ns}$ \\
\hline
\end{tabular}

Acknowledgements The research project was supported by the Italian Ministry for Universities and Scientific and Technological Research (Cofin.2000). The authors wish to express thanks to Pharmanutrients for providing the Conjugated linoleic acid

* $7 \mathrm{~d}$ before parturition **Body Condition Score (CLA) supplement for this project .

\section{References}

Bassaganya-Riera, J., Hontecillas-Magarzo, R., Bregendahl, K., Wannemuehler, M. J. and Zimmerman, D. R. 2001. Effects of dietary conjugated linoleic acid in nursery pigs of dirty and clean environments on growth, empty body composition, and immune competence. Journal of Animal Science 79: 714-721. Bee G. 2000. Dietary Conjugated Linoleic Acid alter adipose tissue and milk lipids of pregnant and lactating sows. Journal of Nutrition 130: 2292-2298. Corino, C., Bontempo, V. and Sciannimanico, D. 2001. Effects of Dietary Conjugated Linoleic Acid on Some Aspecific Immune Parameters and Acute Phase Protein in Weaned Piglets. Canadian Journal of Animal Science, in press. Pariza, M. W., Park, Y. and Cook, M. E. 2001. The biologically active isomers of conjugated linoleic acid. Progress in Lipid Research 40: 283-298. Houseknecht, K. L., Baile C. A., Matteri R. L., and Spurlock, M. E. 1998. The biology of leptin: a review. Journal of Animal Science 76:1405-1420. 